\title{
The cost-quantity relations and the diverse patterns of "learning by doing": Evidence from India
}

\author{
Giovanni Dosi ${ }^{\mathrm{a}}$, Marco Grazzi ${ }^{\mathrm{b}}$, Nanditha Mathew ${ }^{\mathrm{a}, \mathrm{c}, *}$ \\ a Institute of Economics, Sant'Anna School of Advanced Studies, Piazza Martiri della Liberta 33, 56127 Pisa, Italy \\ b Department of Economics, University of Bologna, Piazza Scaravilli 2, 40126 Bologna, Italy \\ c IBIMET-National Research Council, Via Giovanni Caproni, 8, 50145 Florence, Italy
}

\section{A R T I C L E I N F O}

\section{JEL classification:}

D22

D24

L6

$\mathrm{O} 3$

\section{Keywords:}

Learning-by-doing

Learning curves

Product innovation

Process innovation

\begin{abstract}
A B S T R A C T
"Learning-by-doing" is usually identified as a process whereby performance increases with experience in production. Of course such form of learning is complementary to other patterns of capability accumulation. Still, it is fundamental to assess its importance in the process of development. The paper investigates different patterns of "learning by doing", studying learning curves at product level in a catching-up country, India. Cost-quantity relationships differ a lot across products belonging to sectors with different "technological intensities". We find also, puzzlingly, in quite a few cases, that the relation price/cumulative quantities is increasing. We conjecture that this is in fact due to quality improvement and 'vertical' product differentiation. Circumstantial evidence rests on the ways differential learning patterns are affected by firm spending on research and capital investments. Finally, our evidence suggests that "learning", or performance improvement over time is not just a byproduct of the mere repetition of the same production activities, as sometimes reported in previous studies, but rather it seems to be shaped by deliberate firm learning efforts.
\end{abstract}

\section{Introduction}

Theoretical and empirical studies in economics consider "learningby-doing" as a process in which an increase in experience in a particular type of production ('doing') yields an improvement in efficiency ('learning'). Typically the postulated relation is a power law, linking some performance indicator (e.g. unit costs, unit prices, productivity) with an experience indicator (e.g. cumulated production). The evidence, which we shall review below is quite robust. However the simplified version of "learning by doing", henceforth LBD, presents significant drawbacks. First, LBD, as shown in the innovation literature is only one of several, often complementary forms of knowledge accumulation. Second, even when strictly applies, as discussed by, for example, Scott-Kemmis and Bell (2010), it is often considered that learning is a costless activity and an automatic by-product of continued production activities. Third, it is generally assumed that all organizations have the same capacity to learn and there are no differences in absorptive capacities that might lead to differences in the intensity of learning across different organizations. Fourth, only rarely the product characteristics remain in actual fact invariant. Rather, often, the object of 'learning' improves its performance but at the same time, its production costs.
In this work we investigate the existence, shape and slope of learning curves in a developing country, namely India, at the productlevel, conditioning on firms' and sectoral characteristics. In particular, we shall analyze, first, how the slope of the learning curves are affected by R \& D and fixed investment activities, and second, by the timing of entry of the firm in any one production activity, and hence, indirectly by the positioning of the firm along the life cycle of a product (and thus, the possible knowledge spillovers it gains from older incumbents). Needless to say, the understanding of the determinants of the very existence and slope of learning curves is not only important in its own right as a part of the microeconomics of innovation, but bear far reaching implications for the very analysis of the determinants of growth - in general and especially with respect to emerging economies. For example, would one find widespread and relatively uniform learning curves, that would give support to the view whereby knowledge is simply the "unintentional side effect of the production of a conventional good" (Romer, 1990) and, dynamically, the notion that the "the larger the rate of production, the greater the learning experience" (Rosen, 1972). Indeed a wide ensemble of growth models are built in such notion: among others, Rosen (1972); Romer (1986); Lucas (1988); Stokey (1988); Young (1993) and De Liso et al. (2001).

Conversely, were one to find a great inter-product/inter-

\footnotetext{
* Corresponding author at: Piazza Martiri della Liberta 33, 56127 Pisa, Italy.

E-mail addresses: giovanni.dosi@santannapisa.it (G. Dosi), marco.grazzi@unibo.it (M. Grazzi), nandithamathew@gmail.com (N. Mathew).
} 
Table 1

Major reviews, empirical and theoretical studies on learning curves.

\begin{tabular}{|c|c|}
\hline Wright (1936) & Put together earlier USAF and supplier company improvement curve studies. \\
\hline Rigdon (1944) & Labour productivity trends in the WW II US airframe industry. \\
\hline Searle (1945) & Labour and time trends in WW II US shipbuilding industry. \\
\hline Middleton (1945) & Reports productivity performance in WW II airframe manufacturing. \\
\hline Carr (1946) & Critical review applications of learning curve models. \\
\hline Mensforth (1947) & Comparison of cost-quantity trends of aircraft production in UK and USA. \\
\hline Stanley (1949) & Empirical study of time to achieve peak rate of production in WW II airframe industries. \\
\hline Arrow and Arrow (1950) & Productivity trends in WW II US airframe industry. \\
\hline Arrow et al. (1951) & Labour productivity trends in WW II US airframe industry. \\
\hline Asher (1956) & Improvement trends in the WW II and post-war US airframe industry. \\
\hline Alchian (1963) & Labour productivity trends in WW II US airframe industry. \\
\hline Rapping (1965) & Improvement in man-hour productivity in WW II US shipbuilding industry. \\
\hline Young (1966) & Critical review of applications of the learning curve concept. \\
\hline Colasuonno (1967) & Review of progress curves through review and evaluation of articles and reports. \\
\hline Brockman and Dickens (1967) & Labour productivity trends for nine cargo aircrafts in the US aircraft industry. \\
\hline Hartley (1969) & Discusses the application of learning curves in UK aircraft production outlays. \\
\hline Orsini (1970) & $\begin{array}{l}\text { Review of progress curves \& develops a three-dimensional learning curve model by including the production rate as a second } \\
\text { explanatory variable. }\end{array}$ \\
\hline Dosi (1984) & Models cost and pricing procedures under conditions of technical change. \\
\hline Lieberman (1984) & Documents variations in the slope of learning curve linked to differences in R \& D \& capital intensity. \\
\hline Gruber (1992) & Learning curve in semiconductor chips; heterogeneity of learning across products (chip types). \\
\hline Irwin and Klenow (1994) & Learning-by-doing spillovers within the semiconductor industry. \\
\hline Jovanovic and Nyarko (1996) & Develops one-agent Bayesian model of LBD and technology choice. \\
\hline Argote (1996) & Reviews organizational learning \& forgetting and evidence about whether learning transfers across organizations. \\
\hline Hatch and Mowery (1998) & Analyses the relationship between process innovation and learning-by-doing in the semiconductor industry. \\
\hline McDonald and Schrattenholzer (2001) & Estimates learning rates for energy conversion technologies. \\
\hline Jovanovic and Rousseau (2002) & Empirical learning curves for three general-purpose technologies: Computers, electricity, and the internal combustion engines. \\
\hline Lapré and Tsikriktsis (2006) & $\begin{array}{l}\text { Explore whether customer dissatisfaction follows a learning-curve pattern looking at trends in customer complaints against } 10 \text { largest } \\
\text { airlines. }\end{array}$ \\
\hline Schoots et al. (2008) & Learning curves using cost data for hydrogen production process; No cost reduction is found. \\
\hline Grubler (2010) & Cost trends in specific reactors in time; finds that reactor construction costs increase in time. \\
\hline Funk and Magee (2015) & Empirical evidence on cost and performance improvements even with no commercial production; but with deliberate R \& D efforts. \\
\hline
\end{tabular}

technological/inter-firm diversity in learning rates one would be forced to bring more "Schumpeterian" and "evolutionary" elements into the explanation, related to both the specificities of the different technologies and the characteristics and strategies of different firms and it would also carry different policy implications. More generally, such evidence should urge to finer accounts of the complementarity between production-related learning on the one hand, along with other drivers of knowledge accumulation, on the other. So, as Romer (1990) in a selfcritical mood puts it, considering the importance of determinants of knowledge accumulation other than sheer learning-by-producing, "if the fundamental policy problem is that we have too many lawyers and MBAs and not enough engineers, a subsidy to fixed capital accumulation is a weak, and possibly counterproductive, policy response" (p. S94).

A normative implication, much relevant for the case of India, is related to industrial policies in developing countries that aim at nurturing an environment that might encourage the creation and growth of new firms, the so called infant industry argument. In this respect, all the evidence on LBD militates in favour of institutional set-ups supporting infant industries based on the idea that production, even if not profitable at present, could greatly improve over time (see within an enormous literature, e.g. Bardhan, 1971; Succar, 1987; Bairoch, 1995; Rodrik and Yoon, 1995; Pack and Saggi, 2006; all the way to Cimoli et al., 2009). Basically, LBD implies one of the forms of dynamic increasing returns. The argument is even stronger in the case of developing economies with larger markets, as India, for instance, where firms in their early phase can take advantage of a large domestic market to increase their scale of operations and exploit internal increasing returns. Note, however, that in a good deal of the policy debate much of the attention was placed in the mere "automatic" experience in production, with much less attention on the firm-level learning strategies or inter-sectoral differences in learning modes. Not enough attention has been generally devoted to the so-called "non-doing"1 mechanisms of learning and hence also policy interventions were not much focused on the more deliberate efforts undergone by firms to improve their efficiencies, which might take the forms of investment in tangible assets embedding more recent technologies or $\mathrm{R} \& \mathrm{D}$ spending. More generally, learning is likely to be shaped and modulated by the different modes by which firms learn, imitate and innovate in different technologies and sectors. An initial but insightful taxonomization of such modes is in Pavitt (1984). And we shall make use of it in order to begin to taxonomize learning patterns.

The paper proceeds as follows. In the next section, we provide a critical review of previous studies on LBD. Section 3 describes the data and variables used in the paper. In Section 4, we look at the costquantity relationships across products as revealed by learning curves and learning coefficients. Section 5 presents the observed heterogeneity in the cost-quantity relationships among different products and different sectors, while Section 6 attempts to relate it to different firmspecific characteristics. Section 7 deals with the effect of market experience in mode of entry of firms. Section 8 concludes.

\section{Studies on LBD and its applications}

The notion of "learning-by-doing" was first put forward in the 1930s and 1940s, thanks to studies of aircraft and ship production. The learning curve, originally born in the engineering discipline when T. P. Wright, the director of engineering of the Curtiss-Wright Corporation, began to plot out "the effect of quantity production on cost" (Wright, 1936). The resulting graphs reported a log-log relation between labour required per

\footnotetext{
${ }^{1}$ The term "non-doing" was used by previous studies, for instance, Bell (1984). More generally, the evidence on 'on-line' vs. 'off-line' learning is discussed in Dosi and Nelson (2010).
} 
unit of output and the cumulative volume of production, suggesting a reduction of unit costs by $20 \%$ with each doubling of output volume. In most other studies that followed, the basic power law relation between costs and quantity appeared to fit the data quite well in a wide range of industries including, but not limited to, shipbuilding, machine tools, specialty chemicals, and semiconductors (Arrow and Arrow, 1950; Arrow et al., 1951; Alchian, 1963; Dutton and Thomas, 1984; McDonald and Schrattenholzer, 2001; Argote and Epple, 1990). Table 1 provides a summary of few of the works on LBD. However, most of these studies provide limited information about the causes of improved performance. One interpretation focuses upon some form of collective improvements in production activities, even holding the capital equipment unchanged. Lundberg (1961) called the "Horndal effect" the observation that at the Horndal steel works plant in Sweden with no new investment for a period of 15 years, still productivity (output per man hour) rose on the average close to 2 percent per annum. Therefore, he suggests, the increasing performance should be imputed to learning from experience. As known, that cumulative production-productivity relation has been a source of inspiration also for the seminal theoretical contribution on learning-bydoing by Arrow (1962).

Following works also emphasized the importance of factors beyond mere physical production, like spending on $\mathrm{R} \& \mathrm{D}$ and capital investments as drivers of improved performance. For instance, concerning R \& D, a recent study by Farmer and Lafond (2016) conjectures that, when estimating the improvement rates in technology over time, adding variables like $\mathrm{R} \& \mathrm{D}$ and innovation proxies like patents helps in enhancing the explicatory power of the estimates. Concerning capital investments, productivity improvements appear to be faster when also the capital stock is renewed (Thompson, 2001), although the evidence is sometimes more mixed (Power, 1998; Grazzi et al., 2016).

More generally, it is well established in the economics of innovation literature that "on-line" improvements in dexterity in production activities are just one out of a few modes of learning. Other modes include "off-line" search activities (including of course formal $\mathrm{R} \& \mathrm{D}$ ) primarily directed at product innovation, and at the opposite extreme, the acquisition of capitalembodied advancement in production technologies (see Dosi, 1988; Klevorick et al., 1995; Dosi and Nelson, 2010; Malerba, 1992, among the many others). Technologies and sectors differ in the balance among different learning modes: in this respect, Pavitt taxonomy represents a pioneering attempt to map learning modes into groups of sectors.

In fact, a first major issue still far from settled in the literature is the interaction between improvements in the production methods directly associated with production activities, on the one hand and other forms of "learning". As we shall see in the following, the latter might even imply apparent 'de-learning' in production efficiency, where in fact they yield products characterized by higher quality and performances. Second, but relatedly, crucial issues concerns the robustness of the linearity of the log-log curve itself (as pointed out long ago by Carr, 1946) and the inter-product differences in the slope of such curves (Middleton, 1945). Third, when the fine characteristics of a product change, a subtle issue concerns the measurement of price changes and the degrees to which they capture underlying 'hedonic' variations. Below we shall address all these issues.

\section{Data and variables}

The paper employs firm-level data from the Prowess database, provided by the CMIE (Centre For Monitoring Indian Economy Pvt. Ltd.). Annual reports of companies represent the most relevant source of the database which contains information from the financial accounts of Indian companies. The data span from 1988 to 2012 and cover both publicly and non-publicly traded firms ${ }^{2}$ from manufacturing, services,

\footnotetext{
${ }^{2}$ Around one-third of the firms in Prowess are publicly listed firms. Appendix A pro-
} vides additional information on the database.
Table 2

Summary statistics for product-reporting firms.

\begin{tabular}{llllll}
\hline & 1991 & 1996 & 2001 & 2006 & 2011 \\
\hline Number of Firms & 1875 & 3712 & 5281 & 6264 & 3492 \\
Number of Products & 1268 & 1758 & 1952 & 2114 & 1841 \\
Product-Reporting Firms & 1769 & 3560 & 4983 & 5640 & 3289 \\
Share of single product firms & 0.48 & 0.55 & 0.57 & 0.52 & 0.43 \\
Share of sales of product reporting firms & 0.89 & 0.91 & 0.90 & 0.92 & 0.93 \\
Share of exports of product reporting firms & 0.86 & 0.88 & 0.90 & 0.90 & 0.92 \\
\hline
\end{tabular}

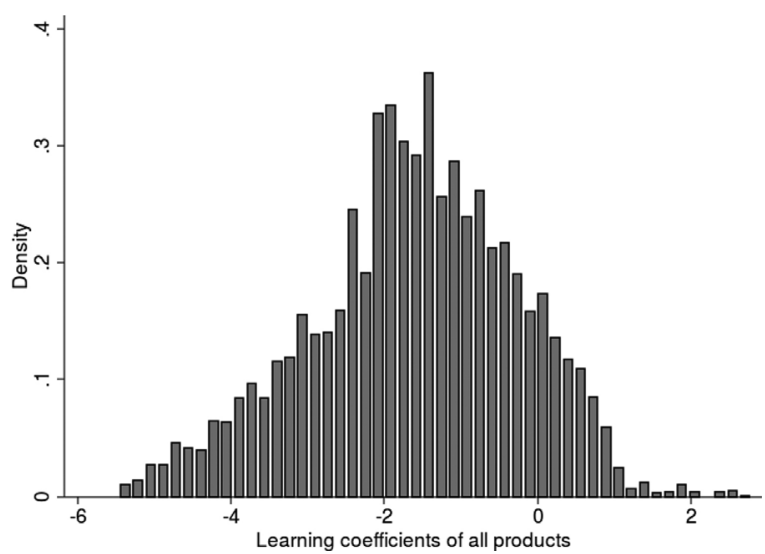

Fig. 1. Distribution of learning coefficients of all products. Note: a negative sign stands for revealed fall in costs/prices.

utilities, and financial industries. As the object of our investigation is the learning process in production, we restrict our attention to manufacturing firms only.

A distinctive feature of Prowess data is that firm's total sales are broken down into the revenues generated by each of the products sold. ${ }^{3}$ The product classification structure is detailed in Appendix A.1. The product-level information is available for 90 percent of the manufacturing firms, that collectively account for more than 90 percent of Prowess' manufacturing output and exports. Firms are required to report not just the names of the products, but also product-level details about production, sales quantity, sales revenues and unit prices. The coverage of product-level information - especially for sales - is extremely good: summing up sales at the product-level yield more than 90 percent of total sales reported through firm balance sheets and similarly for export, see the last two rows of Table 2. Prowess is therefore particularly well suited to investigate how firms adjust their product lines over time. Table 2 reports some summary statistics covering different years to provide evidence of the representativeness of Prowess over time.

\subsection{Variables}

In the literature on learning curves, three variables are typically employed to measure experience: (1) cumulative volume, (2) time and (3) maximum volume. However, the most used is cumulative production volume (Yelle, 1979; Argote et al., 2000). Alternatively, Moore (1965) suggests that the cost of a given technology decreases in time, the so-called "Moore's law", which portrays the relation between an efficiency variable and time. ${ }^{4}$ Mishina (1999) proposed a third "experience" variable, i.e., the maximum output produced to date or maximum proven capacity to date. When a plant is scaling up production, the production system faces unprecedented challenges: hence

\footnotetext{
${ }^{3}$ According to the 1956 Companies Act, firms are required to disclose product-level information on production and sales.

${ }^{4}$ Of course if sales grow exponentially over time, the two measures are equivalent. Empirically we compare the two measures in Appendix C.
} 
Table 3

Relation between cost of production and price of product.

\begin{tabular}{llll}
\hline & $(1)$ & $(2)$ & $(3)$ \\
\hline Unit cost & $0.9497^{* * * *}$ & $0.9942^{* * * *}$ & $0.9938^{* * * *}$ \\
& $(0.0023)$ & $(0.0012)$ & $(0.0012)$ \\
Size & No & No & Yes \\
Time dummies & No & Yes & Yes \\
Sector dummies & No & Yes & Yes \\
Observations & 15,625 & 15,625 & 15,625 \\
$\left(R^{2}\right)$ within & 0.922 & 0.981 & 0.981 \\
$\left(R^{2}\right)$ between & 0.992 & 0.994 & 0.994 \\
$\left(R^{2}\right)$ overall & 0.986 & 0.993 & 0.993 \\
Number of firms & 1620 & 1620 & 1620 \\
$\beta=1$ & $(21.8695)$ & $(4.8333)$ & $(5.3793)$ \\
\hline
\end{tabular}

Last row reports the results of a t-test where the null is $\beta=1$.

$$
* * * p \ll 0.01 \text {. }
$$

Table 4

Learning coefficients ( $\hat{\beta}$ from Eq. (6)) using power function.

\begin{tabular}{|c|c|c|c|}
\hline Product name & Coeff. $(\hat{\beta})$ & Std error & Obs. \\
\hline Pollution Control Equipment & $-0.5023^{* * * *}$ & $(0.0695)$ & 106 \\
\hline Wiring Accessories & $-0.4553^{* * *}$ & $(0.0646)$ & 89 \\
\hline Washing Machines & $-0.3852^{* * *}$ & $(0.0252)$ & 106 \\
\hline Mineral Water & $-0.3687^{\text {*..⿲丿丨 }}$ & $(0.0255)$ & 127 \\
\hline Hand Brakes & $-0.3332^{k * * *}$ & $(0.0241)$ & 137 \\
\hline Road Construction \& Maintenance Machines & $-0.3069^{* * * *}$ & $(0.0607)$ & 70 \\
\hline Room Air Conditioners & $-0.2618^{* * * *}$ & $(0.0208)$ & 191 \\
\hline Refrigerators & $-0.2178^{* * * *}$ & $(0.0256)$ & 70 \\
\hline Condoms & $-0.2174^{* * * * *}$ & $(0.0641)$ & 102 \\
\hline Passenger Cars & $-0.1678^{* * * *}$ & $(0.0217)$ & 136 \\
\hline Writing \& Printing Paper & $-0.1329^{* * * *}$ & $(0.0087)$ & 241 \\
\hline Aluminium foil & $-0.0879^{* * * *}$ & $(0.0106)$ & 114 \\
\hline Detergents & $-0.0857^{* * * *}$ & $(0.0080)$ & 224 \\
\hline Stainless Steel Forging, Flanges \& Allied Pipe & $0.0627^{* * * *}$ & $(0.0074)$ & 528 \\
\hline Helmets & $0.1120^{\text {*** }}$ & $(0.0445)$ & 220 \\
\hline Automobile transmission gear & $0.1130^{* * * *}$ & $(0.0355)$ & 108 \\
\hline Synthetic Filament Yarn & $0.1388^{\text {****}}$ & $(0.0379)$ & 563 \\
\hline Hand watches \& watch components & $0.1676^{\text {*** }}$ & $(0.0698)$ & 165 \\
\hline Oil Cooler & $0.4116^{\text {k****}}$ & $(0.0888)$ & 159 \\
\hline Electrical Porcelains And Insulators & $0.4152^{\text {****}}$ & $(0.0712)$ & 53 \\
\hline Generators & $0.4348^{* * * *}$ & $(0.0714)$ & 288 \\
\hline Can Making Machinery/Industrial machinery & $0.4656^{\text {**** }}$ & $(0.0551)$ & 102 \\
\hline LPG Regulators/Valves & $0.5642^{* * * *}$ & $(0.1103)$ & 120 \\
\hline Perfumery Compounds, Aromatic Spices, Etc. & $0.5908^{* * * *}$ & $(0.0723)$ & 156 \\
\hline Material Handling Equipment & $0.6018^{\text {****}}$ & $(0.0592)$ & 169 \\
\hline
\end{tabular}

such a measure captures the notion of "learning by new experiences" or "learning by stretching" (Mishina, 1999; Lapré and Van Wassenhove, 2001).

In the present study, we measure experience as the cumulated (physical) quantity of a given product manufactured by a firm. Table 4 and Fig. 1 present the statistics on such relation, respectively, for a selection and for all products in our sample. However, in order to compute a proxy for experience in production that can be comparable across firms, we ought to exclude those products that were present in the first year of our sample, since for these products we cannot know either the cumulated production before the beginning of the sample period or the product tenure. ${ }^{5}$

The performance variable that we will be mostly employing is the unit price of the product. Notice that production costs per product for multi-product firms are not available and probably unknown with

\footnotetext{
${ }^{5}$ Note that, due to the increasing number of observations over time, the first year of the dataset is the one with the smallest number of observations. Hence the exclusion of products that were present in the first year comes at a relatively low cost: out of 2281 products that appear over the whole sample period, we only have to drop 343 of these. However, also note that we perform a robustness check in which we include all available products and results are not significantly affected.
}

precision to the firms themselves. In fact, several previous empirical studies have used price data to construct experience curves (Boston Consulting Group, 1970; Abell and Hammond, 1979; Ayres and Martinas, 1992; Neij, 1997; Gruber, 1992, 1998; Irwin and Klenow, 1994; Chung, 2001). ${ }^{6}$ And, indeed, there is a good matching between unit cost dynamics and unit prices whenever the latter are fixed according to some mark-up pricing procedure (Dosi, 1984), whereby price is a multiplicative markup over average cost (for a similar pricing structure, see, among others, Amiti et al., 2014):

$P_{\mathrm{ijt}}=C_{\mathrm{ijt}}\left(1+\mathrm{MU}_{\mathrm{ijt}}\right)$,

where the three terms are, respectively, the unit price $\left(P_{i j t}\right)$, the unit production cost $\left(C_{i j t}\right)$ and the markup $\left(M U_{i j t}\right)$ of firm $i$, for product $j$ at time $t$. In this work we are not interested in the estimation of the markup per se, however, to the extent that Eq. (1) offers an accurate approximation of the pricing behavior of firms, that would provide support to our choice of price as a performance measure even when, as for the case of multi-product firms, information on costs is not available. We can test the validity of our conjecture for the case of single product firms. $^{\text {? }}$

We estimate, using firm-fixed effects, a log transformed version of Eq. (1) in which, short of a precise and direct proxy for MU, $R^{2}$ of the regression captures the share of variance of the change in unit price explained by changes in unitary cost. A high $R^{2}$ is plausibly informative also about the quality of the price-based measure that we employ in the case of multi-product firms, when per-product production costs are not available.

Regression results are reported in Table 3 where we also provide some robustness checks by including time dummies and size, as proxied by $(\log )$ sales of the firm. The correlation is extremely high, ${ }^{8}$ and regression coefficients are very close to one in all the specifications. Even though we observe that the difference of beta from one is statistically significant (as we observe from last row of Table 3), the significance of the test is basically due to large number of observations (which is also revealed by the low standard errors) and hence, basically the economic importance is nil, as social science professionals are also coming to realize.

In the rest of the paper we will be using data from all firms, including multi-product ones, with prices as a proxy for costs of production.

\section{Learning curves and learning coefficients: product-level analysis}

Let us start by investigating the cost-quantity ${ }^{9}$ relationships at the product-level by plotting "learning curves", i.e. the relation between cumulative quantities and prices (or cost) of products. Usually, the learning curve is expressed in the form of a power law ${ }^{10}$ :

\footnotetext{
${ }^{6}$ There are many other related fields, such as energy economics, where it is common to use price as a proxy for cost in the learning-by-doing literature: see for example, Berry (2009); Coulomb and Neuhoff (2006); Junginger et al. (2005); Kobos et al. (2006).

${ }^{7}$ For multi-products firms, it is possible to know the sale price for each product sold, but it is not possible to allocate the share of purchased inputs to each product. It is only for single product firms that it is possible to directly relate the cost of production to the price of the output sold. Here "single product" firms are those that have been producing only one product throughout the whole sample period.

${ }^{8}$ Also note that here, as throughout the paper, monetary variables are deflated with 3digit industry output deflators.

${ }^{9}$ Throughout the paper we use the expression cost-quantity instead of price-quantity, since we use price as a proxy to measure cost. Comments and interpretations in the paper rest on the assumption that cost-price margins of products remain roughly constant over time. The hypothesis is tested in Section 3.

${ }^{10}$ Among others, Dutton and Thomas (1984); McDonald and Schrattenholzer (2001) and Argote and Epple (1990) use this formulation. Also note that, as standard in the literature (see for instance Nagy et al., 2013) we consider a positive sign in front of the $\beta$ at the exponent.
} 


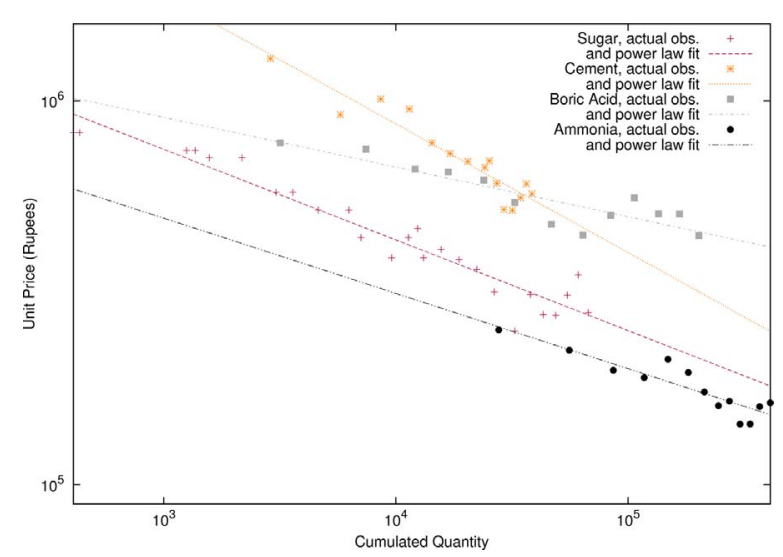

Fig. 2. The relation between cost and quantity (log scale) together with power law fit for selected products; the 'canonical' downward sloping learning curves.

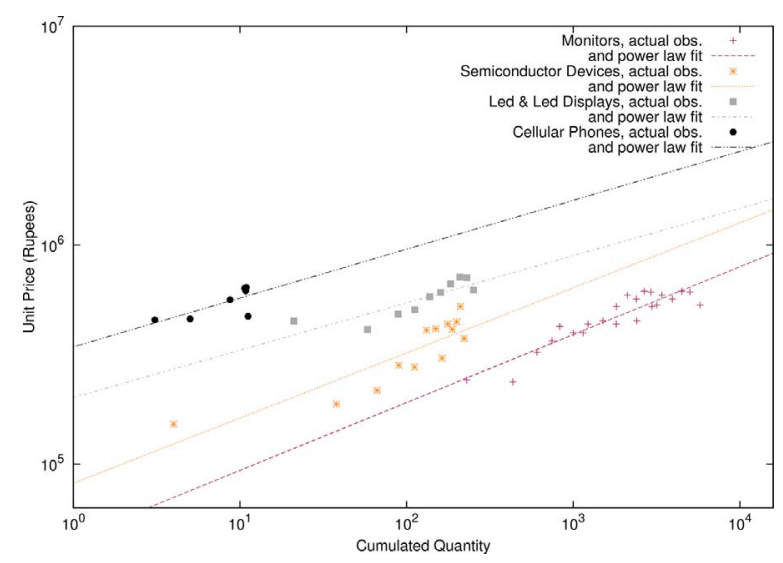

Fig. 3. The relation between cost and quantity (log scale) together with power law fit for selected products; the upward sloping learning curves.

$p=a^{*} q^{\beta}$

where $p$ is the price of the product, $a$ the constant (which can be interpreted as the initial costs), $\beta$ is the scaling factor and $q$ the cumulated quantity produced. Here we focus on estimation of the learning parameters using power and also other three functional forms, generally suggested by previous studies, which include, linear, exponential and logarithmic functions. ${ }^{11}$

We start by investigating the "aggregate" cost-quantity relationship, that is, we pool together observations from all firms producing a given product. We exploit the panel structure of the data, and we look at the price of a given product and its cumulative output. We proceed to perform a firm-level fixed effects regression with the four different functional forms and we check which functional form provides the best representation of the cost-quantity relationship. The estimated equations are the following:

Linear form:

$p_{\mathrm{ijt}}=a_{\mathrm{ij}}+\beta_{j} q_{\mathrm{ijt}}+\epsilon_{\mathrm{ijt}}$

Logarithmic form:

$p_{\mathrm{ijt}}=a_{\mathrm{ij}}+\beta_{\mathrm{j}} \log \left(q_{\mathrm{ijt}}\right)+\epsilon_{\mathrm{ijt}}$

\footnotetext{
${ }^{11}$ Koh and Magee $(2006,2008)$ claim that an exponential function of time predicts the performance of several different technologies. According to Goddard (1982) costs follow a power law in production rates rather than cumulative production. Multivariate forms involving combinations of production rate, cumulative production, or time have been examined by Sinclair et al. (2000) and Nordhaus (2014).
}

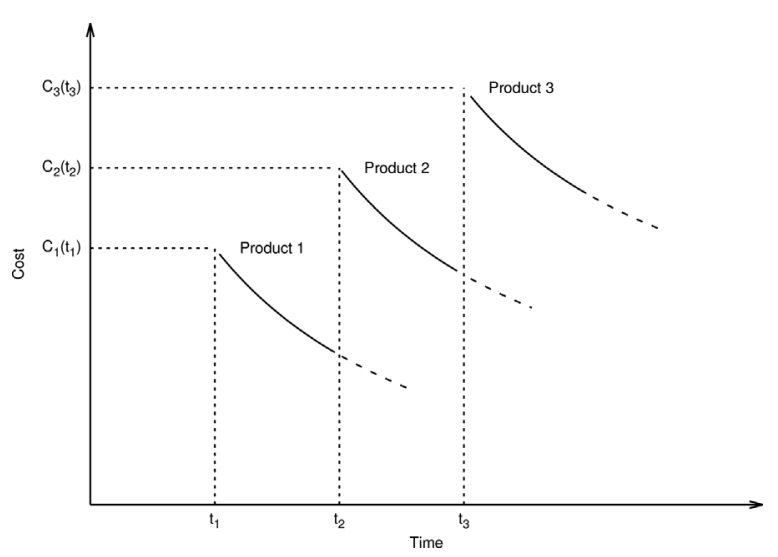

Fig. 4. Learning along the cost curve of one product vs learning to produce new products.

Exponential form:

$\log \left(p_{\mathrm{ijt}}\right)=\log \left(a_{\mathrm{ij}}\right)+\beta_{j} q_{\mathrm{ijt}}+\epsilon_{\mathrm{ijt}}$

Power form:

$\log \left(p_{\mathrm{ijt}}\right)=\log \left(a_{\mathrm{ij}}\right)+\beta_{j} \log \left(q_{\mathrm{ijt}}\right)+\epsilon_{\mathrm{ijt}}$

where $p_{i j t}$ is the price of product $j$ produced by firm $i$ at time $t, q_{i j t}$ is the cumulated quantity of product $j$ produced by firm $i$ at time $t, a_{i j}$ the intercept and $\epsilon_{i j t}$ is the error term.

To investigate which of the functional forms fit best the learning patterns, we compare the goodness-of-fit using $R$ squared as a fit criterion. In line with previous literature, we find that the goodness-of-fit of the power and exponential functions is higher than the linear functions. Similar findings have been reported by Anderson and Schooler (1991) and Wixted and Ebbesen (1997). The average value of $R$ squared is around 0.5 for power and exponential functions, while for linear and $\log$ functions, it is around $0.2 .{ }^{12}$ In what follows, we will be using the parameters of the power law estimation (however using the exponential parameter our general results do not change).

Table 4 reports the learning coefficients estimated using the power law function (Eq. (6)) for a selection of products. First, note that the learning coefficient varies a lot among products. Second, we observe that for quite a few products, the learning coefficient is positive, and thus, hints at an upward sloping cost-quantity curve. This is confirmed when looking at the distribution of coefficients for all products, as reported in Fig. $1 .^{13}$

Fig. 2 illustrates the canonical cost-quantity curves for some selected products obtained by pooling together the firms producing the same product, for some goods displaying a downward sloping costquantity curve. Dots with different symbols represent different products. Each dot with the same symbol represents a pair of (log) cumulated quantity and (log of) price for a given firm in a given year. This evidence is well in line with several other studies that detect a costquantity relationship that is accounted for by a power-law and that applies to a wide variety of technologies (Dutton and Thomas, 1984; McDonald and Schrattenholzer, 2001; Argote and Epple, 1990). Conversely, Fig. 3 offers a graphical account of some of the "positive" learning curves, that is, a positive relationship between unit price (or

\footnotetext{
${ }^{12}$ Since we are comparing log vis-à-vis non-log models, we also perform the following additional check. We take the exponential of the predicted values for the exponential and power model, then we compute the $R^{2}$ as the difference between (exponential of) the observed and predicted values. Note that the average $R^{2}$ hence obtained is 0.4 , which is comparable to values from OLS estimation of the linear models. Nevertheless, the $R^{2}$ of the non-linear models are still higher than the linear models.

13 The mean, standard deviation, skewness and kurtosis of the distribution are -1.60 , $1.35,-0.23$ and 2.84 respectively.
} 


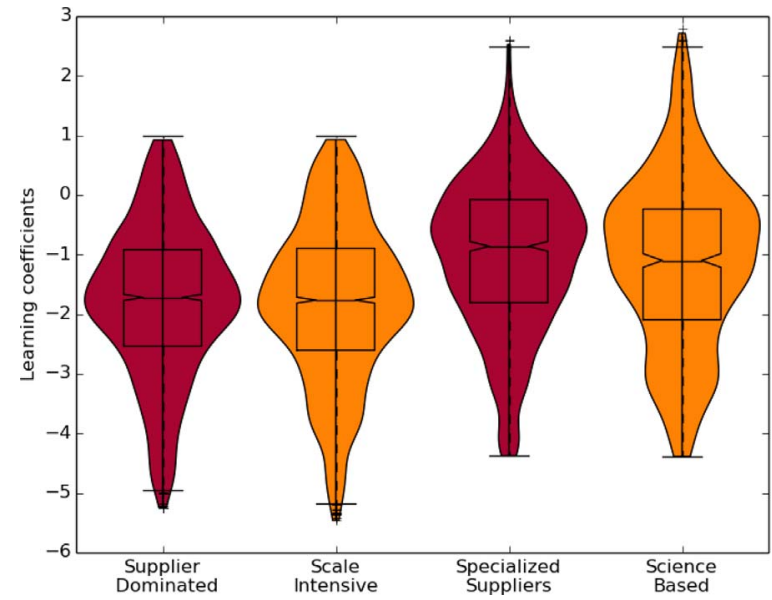

Fig. 5. Distribution of learning coefficients across different Pavitt categories at firm-level. S-D - Supplier Dominated; S-I - Scale Intensive; S-S - Specialized Suppliers; S-B - Sciencebased.

cost) and experience.

The evidence so far shows that, in most of the cases, the costquantity relationship displays a non-linear nature and that such relationship differs across products, even in terms of sign. In the following section we look at the heterogeneity in learning patterns across products and firms, classifying them on the basis of the different technological intensities, as captured by the Pavitt taxonomy (Pavitt, 1984).

\section{Heterogeneity in cost-quantity relationships}

Let us try to investigate the differences in cost-quantity relationships, conditional on the sectors the products belong to.

There could be various product-specific characteristics which might lead to the observed differences in learning patterns. Here, we are interested to investigate the technological characteristics of the product. Our hypothesis is that the products which show a positive relationship between cost and experience undergo systematic quality upgrading over time, hence the observed positive cost-quantity relationship. The general idea is that there are two types of learning, namely one associated with an increased efficiency in the production of a given product and another one linked to the ability of producing new/improved products. The case is illustrated in Fig. 4 with unit costs/prices on the $y$ axis and, for convenience, time on the $x$-axis (recalling that time and cumulated production are equivalent if production grows exponentially).

In a world of pure "process" learning firms would simply go down the Product 1 curve starting from $C_{1}\left(t_{1}\right)$ and following a canonical learning curve. Suppose however that at some point in time the firms introduces "better" product with initial cost $C_{2}\left(t_{2}\right)$ and begins to improve its production capabilities on it, until it introduces yet another improved product with initial cost $C_{3}\left(t_{3}\right)$, etc. Any observer unable to distinguish "learning" along the curve vs. product innovation - as we are not - would actually observe an upward sloping (or for that matter flat) long-term relation between costs/prices on the one hand, and time/cumulated production on the other. ${ }^{14}$ Further, the problem is compounded by the inability to calculate some quality-weighted prices (i.e. proxies for "hedonic prices").

These are all problems which we faced in Dosi (1984) when studying the semiconductor industry. In that case, the pace of both

\footnotetext{
${ }^{14}$ In Appendix B, we attempt to show graphically the price trends of few products where the change(s) in product design can be visually detected.
}

Table 5

Heterogeneity of learning coefficients across different Pavitt sectors: Two Sample Fligner-Policello Robust Rank Order Test.

\begin{tabular}{|c|c|c|c|c|c|}
\hline Sector & Obs. & $\begin{array}{l}\text { Average } \\
\text { placement }\end{array}$ & $\begin{array}{l}\text { Index of } \\
\text { variability }\end{array}$ & F-P statistic & $\begin{array}{l}\text { Two- } \\
\text { tailed } p \text { - } \\
\text { value }\end{array}$ \\
\hline $\begin{array}{l}\text { Supplier- } \\
\quad \text { dominated }\end{array}$ & 24156 & $2.4 \mathrm{e}+04$ & $4.5 e+12$ & 5.654 & 0.000 \\
\hline Scale-Intensive & 47207 & $1.2 \mathrm{e}+04$ & $2.3 e+12$ & & \\
\hline $\begin{array}{l}\text { Supplier- } \\
\text { dominated }\end{array}$ & 24156 & $6.7 e+03$ & $1.8 \mathrm{e}+11$ & 17.648 & 0.000 \\
\hline $\begin{array}{l}\text { Specialized } \\
\text { suppliers }\end{array}$ & 11870 & $1.1 \mathrm{e}+04$ & $8.3 e+11$ & & \\
\hline $\begin{array}{l}\text { Supplier- } \\
\quad \text { dominated }\end{array}$ & 24156 & $4.9 e+03$ & $1.1 \mathrm{e}+11$ & 33.693 & 0.000 \\
\hline Science-based & 7858 & $9.0 e+03$ & $4.2 \mathrm{e}+11$ & & \\
\hline Scale Intensive & 47207 & $6.6 e+03$ & $3.4 \mathrm{e}+11$ & 15.964 & 0.000 \\
\hline $\begin{array}{l}\text { Specialized } \\
\text { Suppliers }\end{array}$ & 11870 & $2.1 e+04$ & $3.2 \mathrm{e}+12$ & & \\
\hline Scale Intensive & 47207 & $4.8 \mathrm{e}+03$ & $2.1 e+11$ & 31.946 & 0.000 \\
\hline Science-based & 7858 & $1.8 \mathrm{e}+04$ & $1.6 \mathrm{e}+12$ & & \\
\hline $\begin{array}{l}\text { Specialized } \\
\text { suppliers }\end{array}$ & 11870 & $4.2 \mathrm{e}+03$ & $7.5 e+10$ & 9.236 & 0.000 \\
\hline Science-based & 7858 & $5.5 e+03$ & $7.5 e+10$ & & \\
\hline
\end{tabular}

product and process innovation has been (and is) so fast that Moore's law applies (see above). ${ }^{15}$

For most products and most technologies, however, this is not the case and the slopes and signs of the price/quantity relation is going to be shaped by the relative balance between product-innovation and process-related learning. In turn such a balance is going to depend also by the type of sector the products belong to. And here is where Pavitt Taxonomy comes in.

\subsection{Sectoral characteristic and learning modes}

Pavitt (1984) distinguishes between sectors and technologies according to sources of technological knowledge, requirements of the users, and appropriability regimes (Pavitt, 1984). He identifies four categories:

(1) Supplier-Dominated sectors which include most traditional activities such as textiles, clothing and agriculture and mainly rely on sources of innovation external to the firm, often equipment-embodied.

(2) Scale-Intensive sectors, characterized by scale-biased technical advances and covering both basic materials and consumer durables, e.g. automobiles. Sources of innovation are both internal and external to the firm and innovation, especially in complex product such as automobiles and consumer durables is related to both product and process.

(3) Specialized Suppliers design and produce industrial machinery and instruments used in most other industrial sectors. Innovation is mostly product-innovation.

(4) Science-based sectors, rely on both in-house R \& D and on university research; they include industries such as pharmaceuticals and electronics. The rates of product innovation are generally quite high while improvement in production efficiency vary a lot across sectors (e.g. very high in the mentioned case of semiconductors; of lesser importance for pharmaceuticals).

In terms of Pavitt's taxonomy one would expect, other things being equal, a dominance of standard downward sloping learning curves in

\footnotetext{
${ }^{15}$ A deeper challenge, as pointed out by a referee, concerns the 'elementary objects', if any, to which learning applies. So for example, in the paradigmatic example of microprocessors, it is not that the cost of each 'unitary transistor' on an Integrated Circuit or a microprocessor goes down. On the contrary, it is the overall cost of a multiplicative number of transistors on a single chip.
} 
Table 6

Learning coefficients of products and innovative characteristics of firms in different Pavitt sectors.

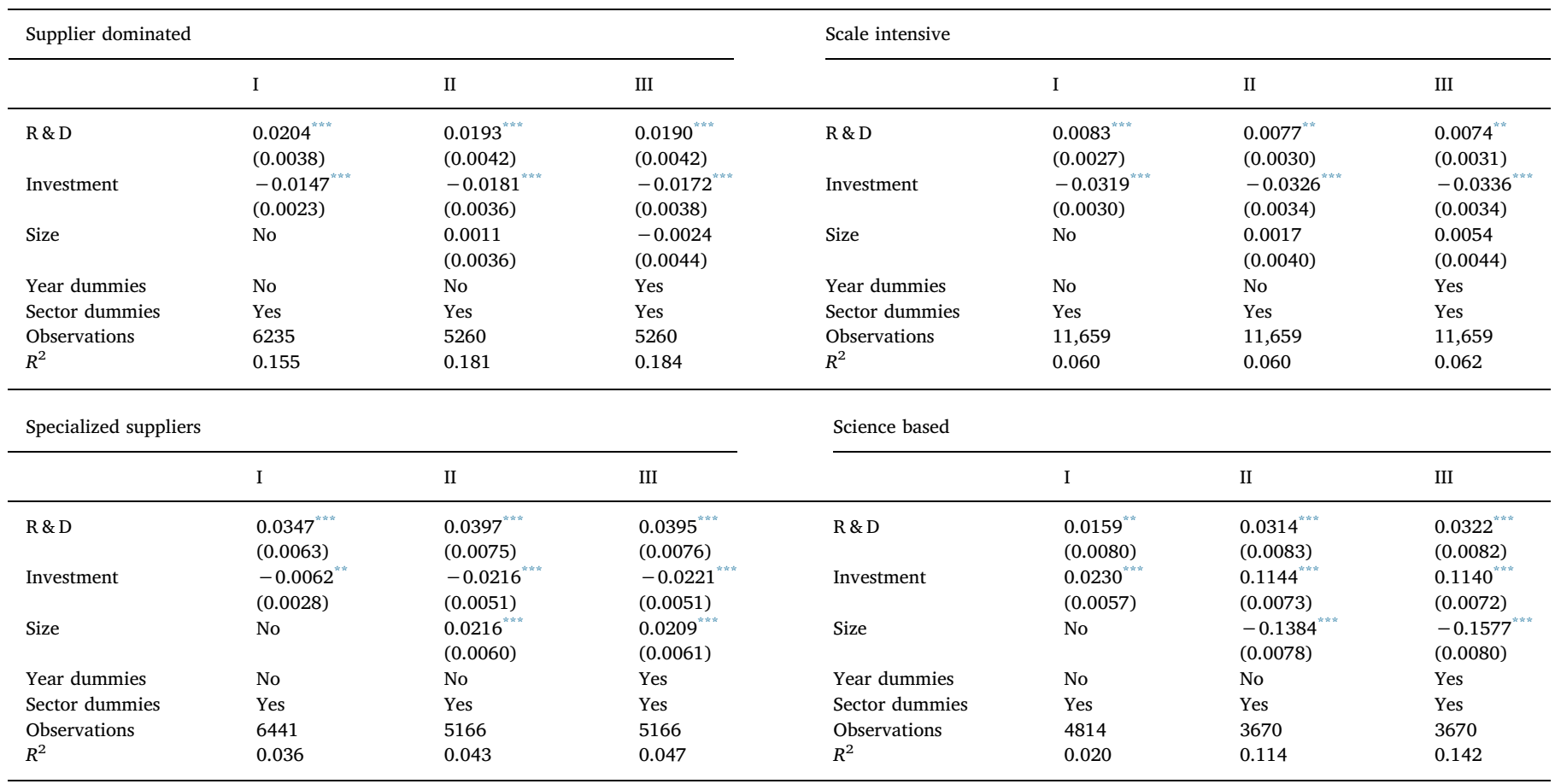

Standard errors in parentheses.

$* * p \ll 0.05$.

$* * * p \ll 0.01$.

technologies/sectors where process learning prevails and a more blurred pictures in the other ones.

Fig. 5 shows the "violin plots" of the distributions of learning coefficients across different Pavitt categories. The plot is a combination of box plot and kernel density distributions. The median of the productlevel learning coefficient for each sector is marked by the central bar and the box indicates the interquartile range as in standard box plots. Indeed the distribution of learning coefficients in the Science-Based and Specialized Suppliers category (S-B and S-S in the figure) is shifted upwards, implying that there are more cases of positively shaped costquantity curves, while most of the observed patterns among Supplier Dominated and Scale Intensive sectors presents negative coefficients (price/costs fall with cumulated quantities).

The difference between the learning parameters across Pavitt sectors is further tested using Fligner-Policello location test (Fligner and Policello, 1981). The null hypothesis for the test is $H_{0}: \theta_{X}=\theta_{Y}$, where $\theta_{X}$ and $\theta_{Y}$ are the population medians of two Pavitt sectors in each pair. ${ }^{16}$ The test assumes that the distribution in each class is symmetric around the class median, but it does not require that the two class distributions have the same form or that the class variances be equal. ${ }^{17}$ Table 5 reports the pairwise Fligner-Policello statistics of the distributions of learning coefficients across different Pavitt categories. A positive and significant F$P$ statistics suggests that the distribution of learning coefficients of the second sector in each pair (for instance, scale intensive sector in the first row) statistically dominates the other. In all the cases we observe that the "learning" coefficients in specialized suppliers and science-based sectors statistically dominate the supplier dominated and scale intensive sectors: that is, there is a higher probability to observe a positively shaped learning curve, i.e. an apparent "anti-learning".

\footnotetext{
${ }^{16}$ The first column of Table 5 gives different pairs of Pavitt sectors.

${ }^{17}$ See Hollander et al. (2014) and Juneau (2007) for details.
}

Interestingly, we also find that for multi-product firms, in 90 percent of the cases, all products produced by the firm display similar costquantity trend. It is further circumstantial evidence of the influence of the nature of underlying technologies which the firms masters on the sign of its 'learning' coefficient. Given the existence of such inter-sectoral differences, we next investigate the presence of firm-specific characteristics associated with such learning patterns.

\section{Cost-quantity relationships and firm characteristics: product vs process innovation}

The main sector of activity of the firms deeply influence the propensity to undertake $R \& D$ and thus the balance between product and process innovation as $\mathrm{R} \& \mathrm{D}$ is to a large extent addressing product innovation/imitation. Still inter-firm variability remains high. Thus, here we investigate the relation between firms' $R \& D$ and investment spending to the observed learning patterns at the firm-product-level.

We perform OLS regressions to investigate the relationship between the observed learning parameters and innovative activities, separately for each Pavitt group of sectors. The proxies we consider for innovative activities are $\log$ of cumulated R \& D for product innovation and log of cumulated investment, possibly capturing capital-embodied, for process innovation. $^{18}$

The estimated model is the following cross-sectional regression:

$\mathrm{LP}_{\mathrm{ij}}=\alpha+\beta_{1} R \& D_{i}+\beta_{2} \operatorname{Inv}_{i}+$ controls $_{i}$

where $L P_{i j}$ is the estimated learning parameter for product $j$ produced by firm $i, \operatorname{In} v_{i}$ is $\log$ of cumulated investment of firm $i$ and $R \& D_{i}$ is the $\log$ of cumulated R\&D of firm $i$. The controls include firm size,

\footnotetext{
${ }^{18}$ See Bogliacino et al. (2012) for a detailed review of innovation, and in particular innovation surveys, in developing countries.
} 
Table 7

Descriptive evidence of firm entry in a given product.

\begin{tabular}{lllll}
\hline $\begin{array}{l}\text { Product } \\
\text { tenure }\end{array}$ & $\begin{array}{l}\text { Higher price } \\
(\%)\end{array}$ & $\begin{array}{l}\text { Lower price } \\
(\%)\end{array}$ & Observations & $\begin{array}{l}\text { Log-difference of } \\
\text { price (Avg) }\end{array}$ \\
\hline $0-5$ & 53.92 & 46.08 & 102 & 0.211 \\
$5-10$ & 45.95 & 54.05 & 407 & 0.604 \\
$10-15$ & 44.44 & 55.56 & 504 & 0.833 \\
$15-20$ & 41.87 & 58.13 & 492 & 0.880 \\
\hline
\end{tabular}

measured as log of sales, year and 2-digit sector dummies. In Eq. (7), RHS variables are at firm-level, since we observe the R\&D and investment spending at firm-level, not disaggregated by single products. The LHS variable, i.e. the learning parameter, is computed at the firmproduct-level, as in Eq. (6).

Table 6 shows the regression results for all four Pavitt sectors. ${ }^{19}$ The first row shows the coefficient values for R \& D. In all the sectors, the coefficients are positive and significant suggesting that, even within the same Pavitt sector, higher spending on $\mathrm{R} \& \mathrm{D}$ is associated with higher values of the learning parameter, that is, higher probabilities to observe a positively shaped "learning curve". ${ }^{20}$ The higher spending on R \& D in turn suggests an underlying quality upgrade of the product over time, i.e. various forms of product improvement/innovation.

Concerning investment intensity, in three out of four Pavitt sectors, the coefficient is significant and negative, as one would expect on the grounds of capital embodied process innovation. This suggests that higher spending on investment is associated with faster improvements in production efficiency. Interestingly, this does not seem to apply to the Science-Based cluster, hinting at the possibility that here new investments are primarily associated with the manufacturing of new products. $^{21}$

The foregoing evidence adds against the notion that the only driver of technological learning is by 'collective experience'. As important as we deem it is (see, among the many others, Dosi et al., 2000), many other modes are there. Some are apparently orthogonal to experience: see Sinclair et al. (2000) and Funk and Magee (2015). ${ }^{22}$ Our findings here suggest an apparent, most likely spurious anti-correlation which appears in a catching-up country. As such it is a puzzle, but also it hints, at normative level, at the possible usefulness of 'infant industry' measure when firms walk up the ladder of product qualities.

\section{Firm entry and learning in the market}

Recall that the foregoing analysis regard product-level learning curves, generally involving unbalanced panels of diverse firms. The results therefore summarize also information about entry, the initial prices at which firms enter in any one product category - possibly with distinct product qualities, and the learning process thereafter. In terms of industrial dynamics, entry of course involves a challenge to the market position of the incumbents, while thereafter learning as such represents a barrier to entry as it establishes a cost differential between

\footnotetext{
${ }^{19}$ We calculate clustered standard error in order to permit general heteroskedasticity and within-cluster error correlation.

${ }^{20}$ Indeed, as one would expect, Pavitt classes do not entirely explain R \& D behaviour (or other aspects) of all firms within the sectors and hence, heterogeneity of firms (also with respect to product innovation), within the Pavitt sectors is the norm.

${ }^{21}$ Note that such results do not change when the learning coefficients employed as dependent variable in the regression are computed including a proxy for previous experience. Results are available upon requests.

22 Other studies, which look at the functional performance metrics of products, employing data on physical attributes or technological characteristics of the product also report evidence on improvement in the characteristics of products not necessarily related to production learning: see, among the others, Martino (1971), Brock (2006), Koh and Magee (2006), Nordhaus (2007), Koh and Magee (2008).
}

Table 8

Relation between "market experience" and firm entry pricing.

\begin{tabular}{|c|c|c|c|c|c|}
\hline & I & II & III & IV & $\mathrm{V}$ \\
\hline Tenure & $\begin{array}{l}0.0617^{\text {*x }} \\
(0.0285)\end{array}$ & $\begin{array}{l}0.1228^{\text {nth }} \\
(0.0514)\end{array}$ & $\begin{array}{l}0.0923^{*} \\
(0.0531)\end{array}$ & $\begin{array}{l}0.1470^{\text {*.*** }} \\
(0.0542)\end{array}$ & $\begin{array}{l}0.1111^{\text {*** }} \\
(0.0559)\end{array}$ \\
\hline Product Sales Share & No & No & $\begin{array}{l}0.0000 \\
(0.0004)\end{array}$ & No & $\begin{array}{l}0.0000 \\
(0.0004)\end{array}$ \\
\hline Firm size & No & No & & $\begin{array}{l}-0.0026^{\text {th }} \\
(0.0009)\end{array}$ & $\begin{array}{l}-0.0027 \\
(0.0010)\end{array}$ \\
\hline Sector dummies & No & Yes & Yes & Yes & Yes \\
\hline Time dummies & No & Yes & Yes & Yes & Yes \\
\hline$N$ & 1867 & 1867 & 1561 & 1794 & 1501 \\
\hline$\left(R^{2}\right)$ & 0.387 & 0.392 & 0.484 & 0.395 & 0.488 \\
\hline Adjusted $\left(R^{2}\right)$ & 0.088 & 0.072 & 0.163 & 0.062 & 0.154 \\
\hline
\end{tabular}

Standard errors in parentheses.

${ }^{*} p \ll 0.10$.

$* * p \ll 0.05$

$* * * p \ll 0.01$.

incumbents and would be entrants over the same product quality.

In Dosi (1984), one sketches out a model of industrial evolution inspired by semiconductors, but as such might be applicable to a wide range of industries, both on the frontier and in the catching up phase characterized by the co-existence of product innovation and productspecific learning-by-doing. The latter continuously induces advantages to incumbents, but that can be always overcome by introduction of new/improved products in the same family, but with improved functionalities. The prediction of the model is a persistent process of entry, jointly with subsequent learning-by-doing, and possibly with new/improved products.

Of course, on the grounds of our data we have no way of accessing the techno-economic features of each product, but a story of persistent late entry cum higher entry prices is consistent with such conjecture. This is what we find indeed in the Indian case. At a finer level of resolution, one would expect, on the grounds of a capability-based theory of the firm (Dosi, 1982; Dosi et al., 2000; Teece and Pisano, 1994) that late entrants which however have learned in related products know also how to produce "better products" at lower costs from the start.

Table 7 shows summary statistics on firm-product entry prices with respect to the average price of the incumbents producing the same good, or in other words, the market price. Market price is defined as the weighted average price of the product at the market level (incumbents) where the weights are the physical quantities of sales of the product. ${ }^{23}$ A firm-product entry might occur either when an existing firm adds a new product to its portfolio or in presence of firm entry, that is when a new firm enters the dataset. Of course, as we are interested in assessing the performance of new firm-product combinations relative to firms that are incumbent in that product-market, we restrict our attention to products for which there are at least 10 other competitors. Column 1 of Table 7 shows the different product tenures, i.e., the number of years the incumbents are producing one product. ${ }^{24}$ Column 2 shows the percentages of firm-product combinations where the firm-product entry occurs at a higher price than the market average. Column 3 shows the number of firm-product combinations where the firm-product entry price is lower than the market price. Column 4 shows the total observations in each product tenure class. Column 5 shows the average of the difference (in logs) between weighted average market price and entrant price. We observe in Table 7 that with increasing product tenure, i.e., the higher the number of years the incumbents are producing

\footnotetext{
23 The average price is computed excluding the new entrant.

${ }^{24}$ In order to precisely measure the tenure of the product, we drop the products that were present in the first year of our sample. For those products indeed, we have no information about the actual year of introduction. Note however that in a robustness check in which we include all observations, results remain the same.
} 
a product, the higher the difference between entrant and market price. In order to provide more detailed evidence, let us estimate the model:

$$
\begin{aligned}
\left(P_{\mathrm{ij}} / \bar{P}_{j}\right)= & \alpha_{j}+\beta_{1} \text { Tenure }_{j}+\beta_{2} \text { Product sales share }_{\mathrm{ij}}+\beta_{3} \text { Firm size }_{i}+\text { year }_{\mathrm{ij}} \\
& + \text { sector }_{i}+e_{\mathrm{ij}}
\end{aligned}
$$

where $P_{i j}$ is price of product $j$ of firm $i, \bar{P}_{j}$ is the weighted average price of the product at the market level as defined before, Tenure ${ }_{j}$ is the number of years the product has been produced by incumbent firms and is our proxy for market experience or knowledge stock at the market level. We control for Product sales share, i.e., the share of sales of the product in total sales of firm in the year of entry and Firm size, measured as $\log$ of gross fixed assets of the firm and we include year and sector ${ }^{25}$ effects. Since we are looking at firm-product entry, a one-time event, we pool the entry events in different years together and hence there is no time dimension in our analysis, in this respect the year dummies allow to control for temporal effect. Therefore, we perform a cross sectional analysis and employ an ordinary least squares regression with product fixed effects. We calculate cluster-robust standard error that permit general heteroskedasticity and within-cluster error correlation.

The results are reported in Table 8 and overall, they suggest that the higher the "age" of the product family, the higher is the ratio of entrant to market price. Hence, the result suggests that firms entering a new product market find more difficult to successfully engage in price competition, the longer is the tenure of the product on the market. Conversely, the size of the "product entrant" has a negative effect on the price-ratio.

\section{Conclusions}

Persistent technological and organizational learning is most likely the fundamental driver of economic dynamics since the Industrial Revolution and underlines all episodes of catching-up ever since (for pertinent discussions, see Freeman, 1987; Cimoli et al., 2009). Learning takes various forms which the economics of innovation has investigated in detail (a critical survey is in Dosi and Nelson, 2010).

One of such ways, is learning-by-doing, that is some relation between experience by making, usually proxied by cumulative production and increasing production efficiencies/falling cost and prices. It is important to notice however that such statistical evidence does not capture only strict learning by experience. On the contrary, it partly capture also those processes of capability accumulation, technological adoption, imitation, and finally cumulative innovation, at the level of firms and sectors (more in Dosi and Nelson, 2010 and in the case of Korean development, see Kim, 1999; Lee, 2013).
The evidence is quite robust, mostly collected so far on industries in developed economies. But does it properly apply also to developing ones? And what explains the inter-sectoral/inter-product differences in the apparent learning patterns, if any?

In this work, on Indian manufacturing, we do corroborate in a good deal of cases the power law relation of cost/prices vs cumulated produced quantities. At the same time, we find, first, a wide variation in learning coefficients which still demands satisfactory explanations. Second, relatedly, some relations appear to be positive, that is, an apparent "anti-learning". Such patterns, however are consistent with some circumstantial evidence according to which learning tends to relate more to product than process innovation. Third, product innovation also explains why late entry in the same product family occurs notwithstanding learning curves, which as such represent entry barriers in favour of incumbents.

Finally, note that our work, and more in general, the recent increasing availability of product level data, discloses new research trajectories that one only started to investigate here. For instance, in the development process, to what extent corporations are able to successfully transfer specific production knowledge accumulated over the years in a given product to a different one? And, relatedly, within a firm, does one observe different learning patterns for products that compete in foreign markets vis à vis products sold only domestically? This is just part of the beginning of the opening-up of the black-box of catching-up learning. In turn, these endeavors ought to be considered as an essential part of the investigation of the microeconomics of capability accumulation, as such an essential part of the dynamics of development.

\section{Acknowledgements}

We thank Martin Bell, Tommaso Ciarli, Alex Coad, Alessandro Nuvolari, Luciano Pietronero, Emanuele Pugliese, Gerald Silverberg, Andrea Zaccaria, and several participants at the 11th ENEF meeting in Manchester (2014), 15th ISS Conference in Jena (2014), 7th Asialics in Daegu (2014), 12th Globelics in Addis Ababa University (2014), the 9th EMAEE conference in Maastricht (2015), 13th Globelics conference in Havana (2015), the 2nd annual conference of the International Association of Applied Econometrics in Thessaloniki (2015), SPRU and LEM seminars for their insightful comments. We gratefully acknowledge the research support by the IBIMET-CNR (grant CrisisLabProCoPe) and European Union Horizon 2020 Research and Innovation programme under Grant Agreement No. 649186 - ISIGrowth. The usual disclaimers apply.

\section{Appendix A. Data details}

As mentioned in Section 3, the data are from Prowess database, provided by the CMIE (Centre For Monitoring Indian Economy Pvt. Ltd.). Prowess is a database of active business entities for which information related to their financial performance is available. By "active" business entities, CMIE means those business entities that are not mere registrations without any activity. By "business entities" CMIE implies that it is not restricted to only registered companies. Prowess do not cover the universe of active business entities, even though it is the largest and most comprehensive database on the financial performance of Indian business entities. The companies covered account for around 70 percent of industrial output, 75 percent of corporate taxes, and more than 95 percent of excise taxes collected by the Government of India. Earlier studies have used the same database at the firm-level, such as Topalova and Khandelwal (2011); Balakrishnan et al. (2000) and Krishna and Mitra (1998) to study the impact of reforms on productivity growth of firms and Kumar and Aggarwal (2005) to study the the determinants of R \& D behaviour and the impact of reforms on R \& D behaviour.

Few studies already used the same firm-product-level data. Among these Goldberg et al. (2010a,b) study the relationship between declines in trade costs, the imports of intermediate inputs and domestic firm product scope; whether Goldberg et al. (2010a,b) focus on the characteristics of multi-product firms and the link between product rationalization and trade reforms in India.

Below, we present some description on the product data used for the study. Table 2 in the text reports summary statistics of product-reporting firms.

\footnotetext{
${ }^{25}$ Here, the sector is defined as the main sector of economic activity of the firm, at 2 digit National Industry Classification.
} 
Table 9

Example of the nested industry/product structure of Prowess. Source: Prowess database.

\begin{tabular}{|c|c|c|c|}
\hline NIC & Product code & & Description \\
\hline 11 & & products & Manufacture of beverages \\
\hline \multirow[t]{9}{*}{1103} & & & $\begin{array}{l}\text { Manufacture of malt liquors, beer and other } \\
\text { alcohol }\end{array}$ \\
\hline & 050703010000 & & Malt spirit distilled \\
\hline & 051401040000 & & Soda/Carbonated water \\
\hline & 051403000000 & & Beer \\
\hline & 051404010000 & & Sparkling wine \\
\hline & 051406000000 & & Potable alcohol \\
\hline & 051406010000 & & Indian made foreign liquor \\
\hline & 051406010200 & & Heritage liquor \\
\hline & 051406010300 & & Scotch \& whiskey \\
\hline 15 & & products & Manufacture of leather and leather products \\
\hline \multirow[t]{9}{*}{1512} & & & $\begin{array}{l}\text { Manufacture of consumer goods of leather } \\
\text { and substitutes }\end{array}$ \\
\hline & 070202040000 & & Shopping bags/carry bags \\
\hline & 070202060000 & & Leather hand bag \\
\hline & 070202070000 & & Wallets and leather purses \\
\hline & 070203000000 & & Leather garments and accessories \\
\hline & 070203010000 & & Leather jackets \\
\hline & 070203020000 & & Leather gloves \\
\hline & 070203040000 & & Leather belts \\
\hline & 070203050000 & & Industrial leather hand gloves/apron \\
\hline \multirow[t]{9}{*}{1520} & & products & Manufacture of leather footwear \\
\hline & 070601000000 & & Full leather shoes \\
\hline & 070602000000 & & Canvas shoes \\
\hline & 070603000000 & & Full shoes or boots \\
\hline & 070604000000 & & Slippers \\
\hline & 070605000000 & & Plastic footwear \\
\hline & 070606000000 & & Footcare products \\
\hline & 070607000000 & & Shoe uppers \\
\hline & 070608000000 & & Shoe soles/heels \\
\hline
\end{tabular}

\section{A.1 Product-level classification}

All companies in the Prowess database are mapped to a product or a service in CMIE's standardized products and services classification. This mapping reflects the company's main economic activity during a year. ${ }^{26}$

The product and services classification developed by CMIE is based on the Indian Trade Classification (ITC) which, in turn is based on the Harmonized Commodity Description and Coding System, commonly known as the HS. ${ }^{27}$ CMIE's standardized products and services classification has a hierarchical or tree-like structure in which each broad group, for instance, beverages or leather products is in turn split into narrower categories. At the end of this branching process one finds the singular products. Table 9 offers just an example of such hierarchical structure for the branches of beverages and leather products, the full classification is available through the data provider. Notice that, as it happens also with other comparable classifications of sectors and products, the highest level of detail might vary across different branches. In this respect, in Goldberg et al. (2010a,b) it is argued that the level of disaggregation provided in CMIE is just a variation in the product detail, such variation being a fundamental feature of sectors rather than emphasizing issues with the data. The Prowess database contains a total of 2411 products linked to 293 five-digit NIC industries across 22 manufacturing sectors (two-digit NIC codes). Among these, we remove the products defined only at 2 digit, as they identify broad categories of products which might display a high degree of variability, which finally leaves us with 2281 products.

\section{A.2 Matching from products to Pavitt sectors}

The linking between the products and the NIC industries are provided by CMIE (the data providing company). The NIC follows the United Nation's International Standard Industry Classification (ISIC). As such, NIC 2008 classification has a one-to-one correspondence to ISIC Rev. 4 at 4digit level. A detailed mapping of industrial activities to Pavitt sector is provided in Dosi et al. (2008). The concordance from NAICS and ISIC Rev. 4 is based on the United Nation's concordance file (available at the UNSTATS website). ${ }^{28}$

\section{Appendix B. Evidence of changes in product design}

Here we attempt to show graphically the price trends of few products where the change(s) in product design can be visually detected. Fig. 6 shows learning curves for six products, where it is possible to detect a rather sharp trend in prices over a few years, which might be attributable to changes in product design. For example, the first plot on top-left of Fig. 6 shows the price trend for the product CD/DVD, where we observe a sudden increase in price in the year 2000, probably because the firm started producing DVDs instead of CDs, hence a change in the product characteristics.

\footnotetext{
${ }^{26}$ A company is classified under a particular industry if more than half of its sales originates from the particular industry or industry group. The industry group could be any product or a product group in the CMIE products and services classification structure.

27 The ITC system would only cover commodities but not services and utilities. However, CMIE has added them for its classification system.

28 The classification was lastly retrieved on March 2017 from: http://unstats.un.org/unsd/cr/registry/regot.asp? Lg $=1$.
} 

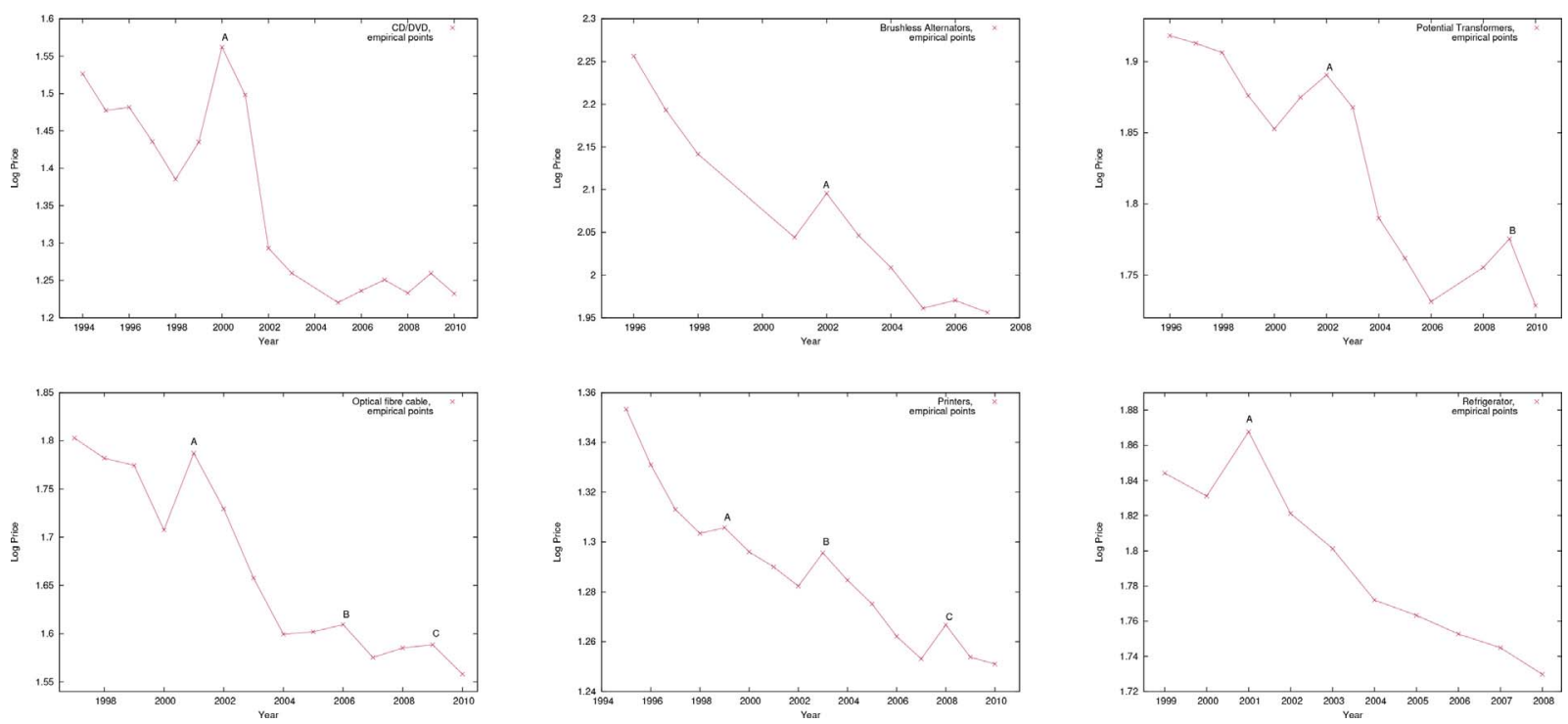

Fig. 6. Learning curves of selected products pointing to changes in product design.

\section{Appendix C. The proximate equivalence of Moore's law and Wright's law}

Straightforwardly, "Moore's law" and "Wright's law" are equivalent if cumulated production grows exponentially over time: for some evidence, see Nagy et al. (2013). Moore's law can be formally expressed as

$p=(a) e^{-\beta t}$

where $a$ is a constant (initial cost or price) and $t$ is time. Moore's law here refers to the generalized statement that the cost or price of a given product decreases exponentially with time compared to Wright's law, which tests whether cost decreases at a rate that depends on cumulative production. In fact, empirically, there is a broad equivalence of Moore's and Wright's law. While comparing the Moore's parameter $m$ ( $\beta$ in equation (9)) with the Wright's $w$ (defined as $-\beta$ from Eq. (6) in the main text of the paper), we observe a startling similarity between the two. The correlation between both the parameters is around 0.9 and the correlation between the $R$-squared of the two models is 0.95 .

A straightforward explanation for the similarity has been highlighted by Sahal (1979) showing that if the cumulative production, $q$, follows an exponential relationship with time, the Wright and Moore parameters are equivalent. Here, we check for the validity of Sahal's formulation and we start by verifying whether cumulative production, $q_{t}$, follows an exponential function with time:

$q_{t}=a^{*} \exp (\mathrm{gt})$

We indeed find that for all the products in our data, the cumulative production grows exponentially. The left column of Fig. 7 shows three examples of products where production and price are plotted as a function of time.

The right column in Fig. 7 shows the trend of cumulative production in time. We observe that for the products for which the Moore's law is validated, also cumulative production grows exponentially in time. ${ }^{29}$

Eliminating $t$ in Eq. (9) (Moore's) and Eq. (10), would result in Wright's law, with $w=m / g$, where $w$ is the Wright's parameter, $m$ is the exponent of cost reduction (Moore's) and $g$ is the exponent of the increase in cumulative production. We test this equivalence of Wright's and Moore's parameter in Fig. 8 by plotting Wright's parameter against $\mathrm{m} / \mathrm{g}$. The values cluster tightly along the identity line. These results are in line with the evidence in Nagy et al. (2013).

While the equivalence of Wright's and Moore's parameter under exponential growth of output over time can be algebraically proven, the empirical question remains as to why that happens. Nordhaus (2014) tries to rationalize why production follows an exponential trend when cost decreases exponentially in time. He points out that when user-based performance of a product increases, or cost decreases, demand elasticity would result in an increase in demand (and thus production).

\footnotetext{
${ }^{29}$ Notice that our findings should not be interpreted as a suggestion that cumulative production must grow exponentially with time in order for Moore's Law to hold. Till date, to our

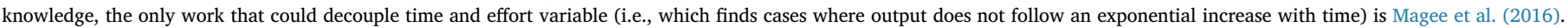
Unfortunately, in this paper since for all the products we observe an exponential growth of cumulative production in time, we cannot test the alternative case.
} 

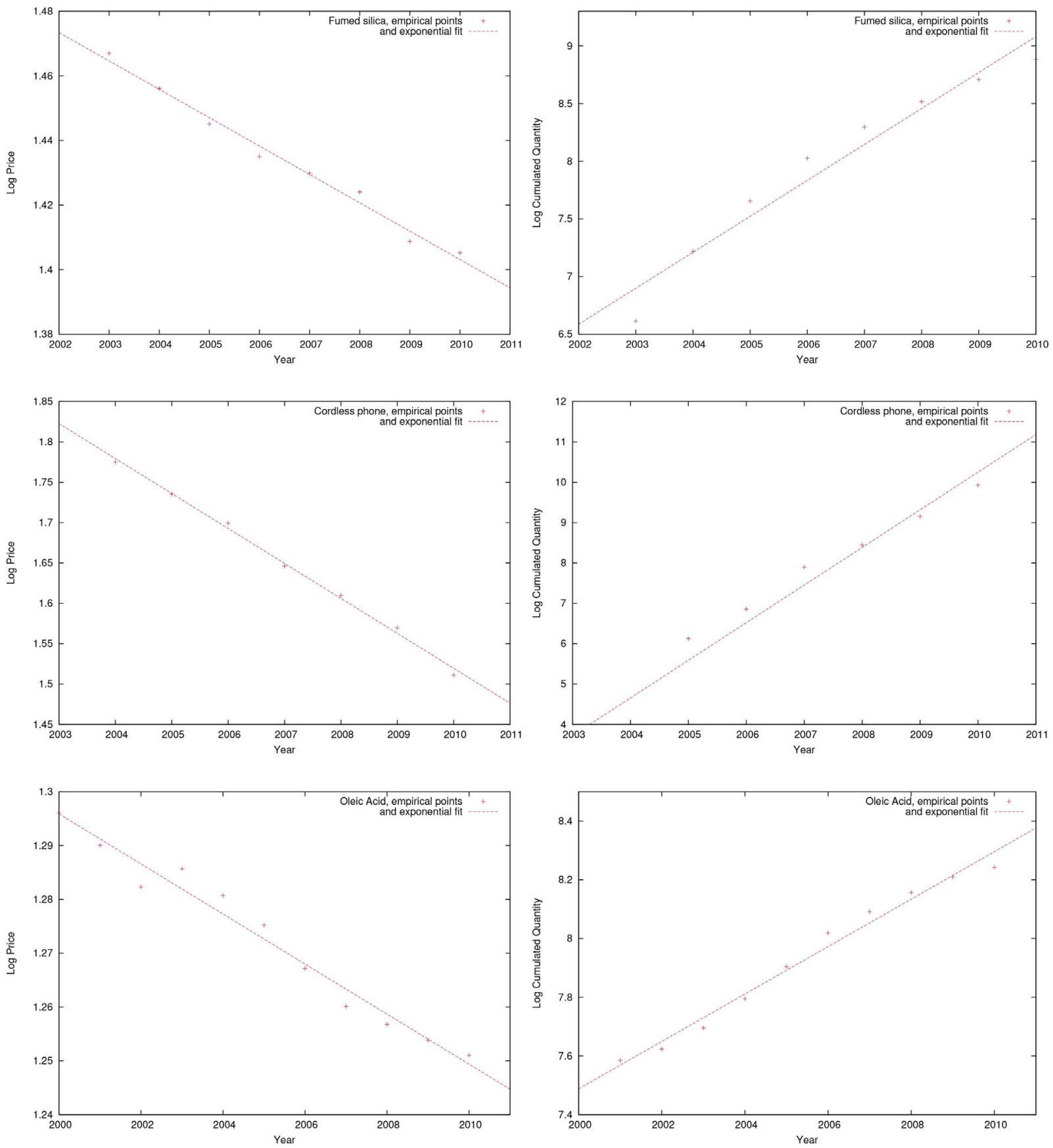

Fig. 7. Three examples showing (log of) price as a function of time (left column) and the (log of) production as a function of time (right column).

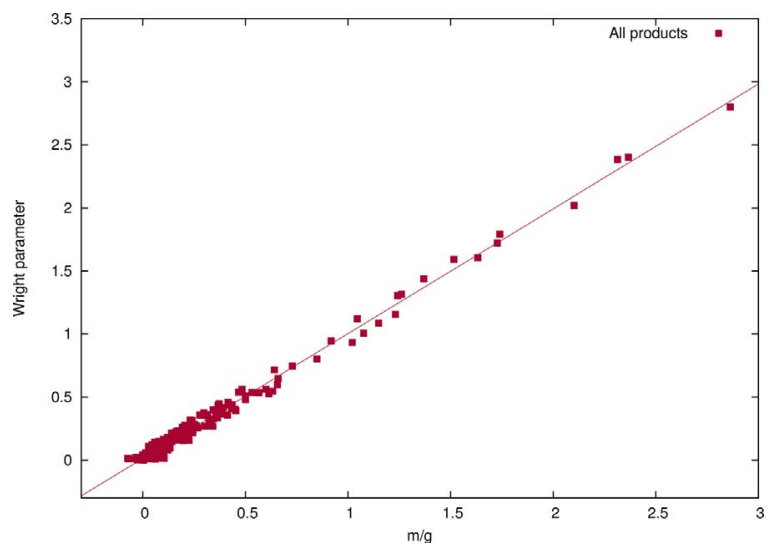

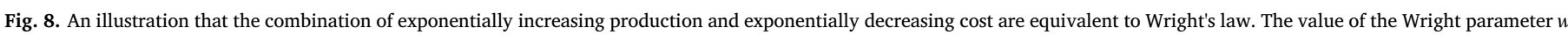
is plotted against the prediction $\mathrm{m} / \mathrm{g}$ based on Sahal (1979), where $m$ is the exponent of cost reduction (Moore's law) and $g$ the exponent of the increase in cumulative production. 


\section{References}

Abell, D.F., Hammond, J.S., 1979. Cost dynamics: scale and experience effects. Strategic Planning: Problems and Analytical Approaches. Prentice-Hall, Englewood Cliffs, NJ.

Alchian, A., 1963. Reliability of progress curves in airframe production. Econometrica 31 (4), 679-693.

Amiti, M., Itskhoki, O., Konings, J., 2014. Importers, exporters, and exchange rate disconnect. Am. Econ. Rev. 104 (7), 1942-1978.

Anderson, J.R., Schooler, L.J., 1991. Reflections of the environment in memory. Psychol. Sci. 2 (6), 396-408.

Argote, L., 1996. Organizational learning curves: persistence, transfer and turnover. Int. J. Technol. Manag. 11 (7-8), 759-769.

Argote, L., Epple, D., 1990. Learning curves in manufacturing. Science 247 (4945), 920-924.

Argote, L., Ingram, P., Levine, J.M., Moreland, R.L., 2000. Knowledge transfer in organizations: learning from the experience of others. Organ. Behav. Hum. Decis. Process. $82(1), 1-8$.

Arrow, K., Arrow, S.S., 1950. Methodology Problems in Airframe Cost-Performance Studies. Technical Report RM-456-PR (DDC No. AD 116556). RAND Corporation.

Arrow, K.J., 1962. The economic implications of learning by doing. Rev. Econ. Stud. 29 (3), 155-173.

Arrow, K.J., Arrow, S.S., Bradley, H.R., 1951. Cost-Quality Relations in Bomber AirFrames. Technical Report RM-538. RAND Corporation.

Asher, H., 1956. Cost-Quantity Relationships in the Airframe Industry. Technical Report R-291. RAND Corporation.

Ayres, R.U., Martinas, K., 1992. Experience and the life cycle: some analytic implications. Technovation 12 (7), 465-486.

Bairoch, P., 1995. Economics and World History: Myths and Paradoxes. University of Chicago Press.

Balakrishnan, P., Pushpangadan, K., Babu, M.S., 2000. Trade liberalisation and productivity growth in manufacturing: evidence from firm-level panel data. Econ. Polit. Weekly 35 (41), 3679-3682.

Bardhan, P.K., 1971. On optimum subsidy to a learning industry: an aspect of the theory of infant-industry protection. Int. Econ. Rev. 12 (1), 54-70.

Bell, M., 1984. Learning and the accumulation of industrial technological capacity in developing countries. In: Fransman, M., King, K. (Eds.), Technological Capability in the Third World. Basingstoke, UK, Macmillan Press, pp. 187-209.

Berry, D., 2009. Innovation and the price of wind energy in the US. Energy Policy 37 (11), 4493-4499.

Bogliacino, F., Perani, G., Pianta, M., Supino, S., 2012. Innovation and development: the evidence from innovation surveys. Lat. Am. Bus. Rev. 13 (3), 219-261.

Boston Consulting Group, 1970. Perspectives on Experience. Boston Consulting Group, Boston, MA.

Brock, D.C. (Ed.), 2006. Understanding Moore's Law: Four Decades of Innovation. Chemical Heritage Foundation, Pennsylvania.

Brockman, W.F., Dickens, F.D., 1967. Investigation of Learning Curve and Cost Estimate Methods for Cargo Aircraft. Air Force Institute of Technology. Technical report AD665464. Wright Patterson Air Force Base, Ohio.

Carr, G.W., 1946. Peacetime cost estimating requires new learning curves. Aviation 45 (4), 220-228.

Chung, S., 2001. The learning curve and the yield factor: the case of Korea's semiconductor industry. Appl. Econ. 33 (4), 473-483.

Cimoli, M., Dosi, G., Stiglitz, J. (Eds.), 2009. Industrial Policy and Development: The Political Economy of Capabilities Accumulation. Oxford University Press, Oxford, New York.

Colasuonno, V., 1967. An Analysis of Progress Curve Conceptual Advances and Progress Curve Uses, Since 1956. Air Force Institute of Technology. Technical Report AD0664952. Wright Patterson Air Force Base, Ohio.

Coulomb, L., Neuhoff, K., 2006. Learning Curves and Changing Product Attributes: The Case of Wind Turbines. Technical Report. Cambridge Working Papers in Economics, University of Cambridge.

De Liso, N., Filatrella, G., Weaver, N., 2001. On endogenous growth and increasing returns: modeling learning-by-doing and the division of labor. J. Econ. Behav. Organ. 46 (1), 39-55.

Dosi, G., 1982. Technological paradigms and technological trajectories: a suggested interpretation of the determinants and directions of technical change. Res. Policy 11, $147-162$.

Dosi, G., 1984. Technical Change and Industrial Transformation - The Theory and an Application to the Semiconductor Industry. McMillan, London.

Dosi, G., 1988. Sources, procedures, and microeconomic effects of innovation. J. Econ. Lit. 26 (3), 1120-1171.

Dosi, G., Gambardella, A., Grazzi, M., Orsenigo, L., 2008. Technological revolutions and the evolution of industrial structures: assessing the impact of new technologies upon the size and boundaries of firms. Cap. Soc. 3 (1), 1-47.

Dosi, G., Nelson, R.R., 2010. Technological change and industrial dynamics as evolutionary processes. In: In: Hall, B.H., Rosenberg, N. (Eds.), Handbook of the Economics of Innovation, vol. 1. Amsterdam, Elsevier, pp. 51-127 (Chapter 4).

Dosi, G., Nelson, R.R., Winter, S. (Eds.), 2000. The Nature and Dynamics of Organizational Capabilities. Oxford University Press, Oxford.

Dutton, J.M., Thomas, A., 1984. Treating progress functions as a managerial opportunity. Acad. Manag. Rev. 9 (2), 235-247.

Farmer, J.D., Lafond, F., 2016. How predictable is technological progress? Res. Policy 45 (3), 647-665.

Fligner, M.A., Policello, G.E., 1981. Robust rank procedures for the Behrens-Fisher problem. J. Am. Stat. Assoc. 76 (373), 141-206.
Freeman, C., 1987. Technology Policy and Economic Performance. Lessons from Japan. Frances Pinter.

Funk, J.L., Magee, C.L., 2015. Rapid improvements with no commercial production: how do the improvements occur? Res. Policy 44 (3), 777-788.

Goddard, C., 1982. Debunking the learning curve. IEEE Trans. Compon. Hybrids Manuf. Technol. 5 (4), 328-335.

Goldberg, P.K., Khandelwal, A.K., Pavcnik, N., Topalova, P., 2010a. Imported intermediate inputs and domestic product growth: evidence from India. Q. J. Econ. 125 (4), 1727-1767.

Goldberg, P.K., Khandelwal, A.K., Pavcnik, N., Topalova, P., 2010b. Multiproduct firms and product turnover in the developing world: evidence from India. Rev. Econ. Stat. 92 (4), 1042-1049.

Grazzi, M., Jacoby, N., Treibich, T., 2016. Dynamics of investment and firm performance: comparative evidence from manufacturing industries. Empir. Econ. 51 (1), 125-179.

Gruber, H., 1992. The learning curve in the production of semiconductor memory chips. Appl. Econ. 24 (8), 885-894.

Gruber, H., 1998. Learning by doing and spillovers: further evidence for the semiconductor industry. Rev. Ind. Organ. 13 (6), 697-711.

Grubler, A., 2010. The costs of the French nuclear scale-up: a case of negative learning by doing. Energy Policy 38 (9), 5174-5188.

Hartley, K., 1969. Estimating military aircraft production outlays: the British experience. Econ. J. 79 (316), 861-881.

Hatch, N.W., Mowery, D.C., 1998. Process innovation and learning by doing in semiconductor manufacturing. Manag. Sci. 44 (11), 1461-1477.

Hollander, M., Wolfe, D.A., Chicken, E., 2014. Nonparametric Statistical Methods. Wiley, Hoboken, New Jersey.

Irwin, D.A., Klenow, P.J., 1994. Learning-by-doing spillovers in the semiconductor in dustry. J. Polit. Econ. 102 (6), 1200-1227.

Jovanovic, B., Nyarko, Y., 1996. Learning by doing and the choice of technology. Econometrica 64 (6), 1299-1310.

Jovanovic, B., Rousseau, P.L., 2002. Moore's law and learning by doing. Rev. Econ. Dyn. 5 (2), 346-375.

Juneau, P., 2007. Nonparametric methods in pharmaceutical statistics. In: Dmitrienko, A. Chuang-Stein, C., D'Agostino, R. (Eds.), Pharmaceutical Statistics Using SAS: A Practical Guide. Cary, NC, SAS Press, pp. 117-150.

Junginger, M., Faaij, A., Turkenburg, W.C., 2005. Global experience curves for wind farms. Energy Policy 33 (2), 133-150.

Kim, L., 1999. Building technological capability for industrialization: analytical frameworks and Korea's experience. Ind. Corp. Change 8 (1), 111-136.

Klevorick, A.K., Levin, R.C., Nelson, R.R., Winter, S.G., 1995. On the sources and significance of interindustry differences in technological opportunities. Res. Policy 24 (2), 185-205.

Kobos, P.H., Erickson, J.D., Drennen, T.E., 2006. Technological learning and renewable energy costs: implications for US renewable energy policy. Energy Policy 34 (13), 1645-1658.

Koh, H., Magee, C.L., 2006. A functional approach for studying technological progress: application to information technology. Technol. Forecast. Soc. Change 73 (9), 1061-1083.

Koh, H., Magee, C.L., 2008. A functional approach for studying technological progress: extension to energy technology. Technol. Forecast. Soc. Change 75 (6), 735-758.

Krishna, P., Mitra, D., 1998. Trade liberalization, market discipline and productivity growth: new evidence from India. J. Dev. Econ. 56 (2), 447-462.

Kumar, N., Aggarwal, A., 2005. Liberalization, outward orientation and in-house R \& D activity of multinational and local firms: a quantitative exploration for Indian manufacturing. Res. Policy 34 (4), 441-460.

Lapré, M.A., Tsikriktsis, N., 2006. Organizational learning curves for customer dissatisfaction: heterogeneity across airlines. Manag. Sci. 52 (3), 352-366.

Lapré, M.A., Van Wassenhove, L.N., 2001. Creating and transferring knowledge for productivity improvement in factories. Manag. Sci. 47 (10), 1311-1325.

Lee, K., 2013. How can Korea be a role model for catch-up development? A 'capabilitybased' view. Achieving Development Success: Strategies and Lessons from the Developing World 25.

Lieberman, M.B., 1984. The learning curve and pricing in the chemical processing industries. RAND J. Econ. 15 (2), 213-228.

Lucas, R.J., 1988. On the mechanics of economic development. J. Monet. Econ. 22 (1), 3-42.

Lundberg, E., 1961. Produktivitet och rdntabilitet. P. A. Norstedt and Soner, Stockholm.

Magee, C.L., Basnet, S., Funk, J.L., Benson, C.L., 2016. Quantitative empirical trends in technical performance. Technol. Forecast. Soc. Change 104, 237-246.

Malerba, F., 1992. Learning by firms and incremental technical change. Econ. J. 102 (413), 845-859.

Martino, J., 1971. Examples of technological trend forecasting for research and development planning. Technol. Forecast. Soc. Change 2 (3-4), 247-260.

McDonald, A., Schrattenholzer, L., 2001. Learning rates for energy technologies. Energy Policy 29 (4), 255-261.

Mensforth, E., 1947. Airframe production. Proc. Inst. Mech. Eng. 156 (1), 24-38.

Middleton, K.A., 1945. Wartime productivity changes in the airframe industry. Mon. Labor Rev. 61 (2), 215-225.

Mishina, K., 1999. Learning by New Experiences: Revisiting the Flying Fortress Learning Curve. Chicago, University of Chicago Press.

Moore, G.E., 1965. Cramming more components into integrated circuits. Electron. Mag. 38 (8), 114-117.

Nagy, B., Farmer, J.D., Bui, Q.M., Trancik, J.E., 2013. Statistical basis for predicting technological progress. PLoS ONE 8 (2), e52669.

Neij, L., 1997. Use of experience curves to analyse the prospects for diffusion and 
adoption of renewable energy technology. Energy Policy 25 (13), 1099-1107.

Nordhaus, W.D., 2007. Two centuries of productivity growth in computing. J. Econ. Hist. 67 (01), 128-159.

Nordhaus, W.D., 2014. The perils of the learning model for modeling endogenous tech nological change. Energy J. 35 (1), 1-13.

Orsini, J.A., 1970. An Analysis of Theoretical and Empirical Advances in Learning Curve Concepts Since 1966. Air Force Institute of Technology. Technical Report ad875892. Wright Patterson Air Force Base, Ohio.

Pack, H., Saggi, K., 2006. Is there a case for industrial policy? A critical survey. World Bank Res. Obs. 21 (2003), 267-297.

Pavitt, K., 1984. Sectoral pattern of technical change: towards a taxonomy and a theory. Res. Policy 13, 343-373.

Power, L., 1998. The missing link: technology, investment, and productivity. Rev. Econ. Stat. 80 (2), 300-313.

Rapping, L., 1965. Learning and World War II production functions. Rev. Econ. Stat. 47 (1), 81-86.

Rigdon, C., 1944. Analysis of progress trends in aircraft production. Aero Dig. 132, 138.

Rodrik, D., Yoon, C.-H., 1995. Strategic trade policy with potential for import substitution. J. Econ. Dev. 20 (1), 37-56.

Romer, P.M., 1986. Increasing returns and long-run growth. J. Polit. Econ. 94 (5), 1002-1037.

Romer, P.M., 1990. Endogenous technological change. J. Polit. Econ. 98 (5 part 2), S71-S102.

Rosen, S., 1972. Learning by experience as joint production. Q. J. Econ. 86 (3), 366-382. Sahal, D., 1979. A theory of progress functions. AIIE Trans. 11 (1), 23-29.

Schoots, K., Ferioli, F., Kramer, G., Van der, B., Zwaan, 2008. Learning curves for hydrogen production technology: an assessment of observed cost reductions. Int. J.
Hydrogen Energy 33 (11), 2630-2645.

Scott-Kemmis, D., Bell, M., 2010. The mythology of learning-by-doing in World War II airframe and ship production. Int. J. Technol. Learn. Innov. Dev. 3 (1), 1-35.

Searle, A.D., 1945. Productivity changes in selected wartime shipbuilding programs. Mon. Labor Rev. 61, 1132-1147.

Sinclair, G., Klepper, S., Cohen, W., 2000. What's experience got to do with it? Sources of cost reduction in a large specialty chemicals producer. Manag. Sci. 46 (1), 28-45.

Stanley, P., 1949. The Time to Achieve Peak Output With Special Reference to Aircraft Production. Technical Report. College of Aeronautics, Cranfield.

Stokey, N.L., 1988. Learning by doing and the introduction of new goods. J. Polit. Econ. 96 (4), 701-717.

Succar, P., 1987. The need for industrial policy in LDC's - a re-statement of the infant industry argument. Int. Econ. Rev. 28 (2), 521-534.

Teece, D., Pisano, G., 1994. The dynamic capabilities of firms: an introduction. Ind. Corp. Change 3 (3), 537-556.

Thompson, P., 2001. How much did the liberty shipbuilders learn? New evidence for an old case study. J. Polit. Econ. 109 (1), 103-137.

Topalova, P., Khandelwal, A., 2011. Trade liberalization and firm productivity: the case of India. Rev. Econ. Stat. 93 (3), 995-1009.

Wixted, J.T., Ebbesen, E.B., 1997. Genuine power curves in forgetting: a quantitative analysis of individual subject forgetting functions. Mem. Cogn. 25 (5), 731-739.

Wright, T., 1936. Factors affecting the cost of airplanes. J. Aeronaut. Sci. 3, 122-128.

Yelle, L.E., 1979. The learning curve: historical review and comprehensive survey. Decis. Sci. 10 (2), 302-328.

Young, A., 1993. Invention and bounded learning by doing. J. Polit. Econ. 101 (3), $443-472$.

Young, S.L., 1966. Misapplications of learning curve concept. J. Ind. Eng. 17 (8), 410. 